Document downloaded from:

http://hdl.handle.net/10251/158688

This paper must be cited as:

Boni Aristizábal, A.; Lopez-Fogues, A.; Fernández-Baldor, A.; Millan, G.; Belda-Miquel, S. (2019). Initiatives towards a participatory smart city. The role of digital grassroots innovations. Journal of Global Ethics. 15(2):168-182.

https://doi.org/10.1080/17449626.2019.1636115

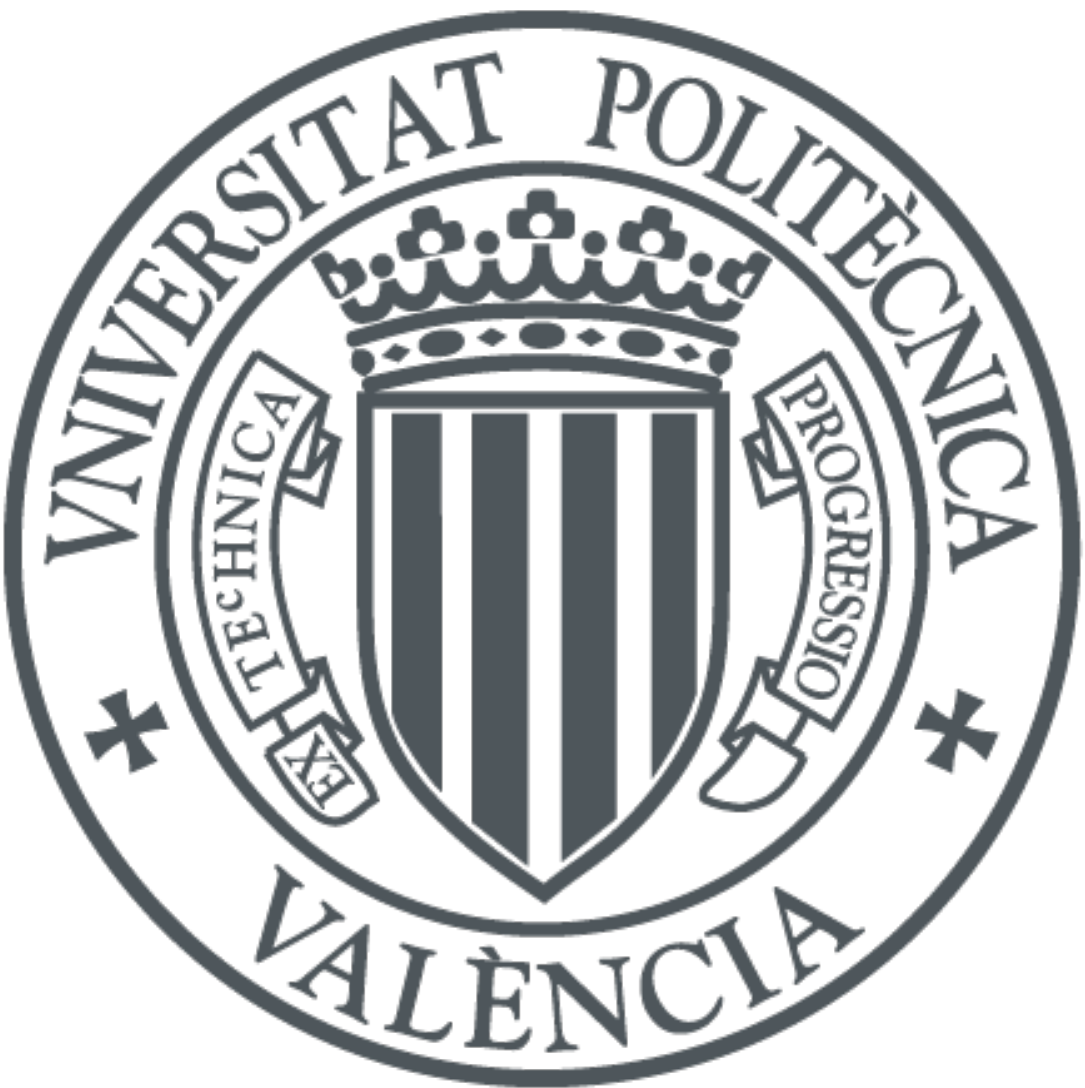

The final publication is available at

https://doi.org/10.1080/17449626.2019.1636115

Copyright Taylor \& Francis

Additional Information 


\section{Initiatives towards a participatory Smart City. The role of grassroots digital innovations.}

Alejandra Boni, Aurora López-Fogués, Álvaro Fernández-Baldor, Gynna Millán and Sergio Belda-Miquel

\section{Introduction. The Smart City, a contested idea}

Over the last decade, the smart city as a concept, discourse and practice, has evolved from a mainly corporate, business-led (often blurred) vision about the use of technology in contemporary cities, to a more expanded vision based on the development of strategies and initiatives from different urban actors. At the core of this approach, however, digital technologies continue to be promoted as the "primary driver for change" (Luque-Ayala and Marvin 2015, 2105). Information and Communication Technologies (ICTs) are seen as crucial tools to stimulate the economic development of cities and to improve urban management, as data, apps and software become part of the urban lexicon (Kitchin, 2015; Luque-Ayala and Marvin, 2015).

However, in the midst of these enthusiastic and positive attitudes regarding the appropriation of technologies to manage and experience the city, there are important critiques of the smart city discourse when it is presented as the only vision for present and future cities. Some stress its self-congratulatory rhetoric (Hollands, 2008 and 2015), the 'by default' apolitical nature of its apparatus (Söderström et al., 2014), or more recently, as literature emerges from other geographies, smart cities as neoliberal urbanism that promotes corporate accumulation of capital, land grabbing and dispossession (Datta, 2015; McFarlane and Söderström, 2017).

A common consensus on what defines the smart city and what it stands for has not been achieved. The intention of this paper is to build on critical definitions that have been offered by scholars who, through observations and empirical work, have moved beyond technological perspectives of the smart city to a more participatory and human centred understanding. A possible definition which encapsulates this perspective is the following: urban settlements that invest in human and social capital, infrastructures, and ICTs (Angelidou, 2014; Caragliu et al., 2011) to nurture knowledge-intensive forms of urban development (McFarlane and Söderström, 2017) that promote human centred, inclusive and participative cities (UN-Habitat, 2016) through participatory management and government (Caragliu et al., 2011). This is essentially an appeal that stresses the need for a plurality of voices to be invited to take part in smart city planning and promote cities' capacity for learning and innovation (Burger-Helmchen, 2015).

In previous work (authors, authors) we named this approach to the smart city the 'Participatory Smart City'; therefore, to characterise what a participatory smart city is, we need to ask ourselves about participation, citizenship and democracy, posing questions such as the following: What type of participation is being enhanced through smart initiatives? Are processes based on "bottom-up" initiatives, or "top-down" decisions? Or are they a combination of both? (Coe et al., 2000). Is the data being collected open, and is it aimed at citizen empowerment? (Gurstein, 2011). Or is it restricted to administrative and managerial purposes? From this perspective, a smart city should promote citizen participation and empowerment, in order to build cities that are not only better managed, but also more democratic and inclusive.

This raises the question of the role that urban stakeholders play in the construction of the smart city. For instance, since the smart city first entered the urban arena, private technology businesses have been leading the discourse and practices; however, more 
recently, we have seen how the local governments of global cities have been adopting the approach in order to achieve better service delivery. Along with this, we have witnessed the rise of small and medium enterprises led by citizens who are innovating with their ideas and disrupting traditional ways of doing things. These citizen-driven innovations are central to the development of this paper. We define them as Digital Grassroots Innovations (DGIs) and argue that they are redefining the role of citizens in the construction of a participatory smart city.

Thus, in this paper we would like to explore the role of DGls in the construction of a more participatory smart city. Our analysis is based on a research project financed by the Spanish Institute of Public Administration. Over a period of eight months, 23 initiatives from four Spanish cities (Santander, Valencia, Bilbao, and San Sebastián) were analysed to understand how collective citizen participation shapes the smart city (authors). In the following section we clarify the characteristics of DGIs and present a profile of different types of digital innovation. In Section 3 we present the theoretical approach to democracy and participation that will help us to understand the different contributions of DGls to the construction of a more participatory smart city. In Section 4, we outline the methodology followed and, in Section 5, we describe and discuss the contribution made by DGls towards a participatory smart city. Finally, in Section 6, we conclude with some final reflections and discuss the implications.

\section{Digital Grassroots Innovations}

There is a burgeoning new strand in literature on innovation that centres on the relevance of social innovation occurring outside the state and the market. This is the innovation that emerges from below, promoted by citizens themselves, to meet their own needs and fulfil their own desires and objectives. In the literature, it is acknowledged that multiple processes of social innovation are taking place in our societies that are not always visible, recognised or valued, which are promoted by "networks of people and organisations that generate new solutions from the bottom-up for sustainable development; solutions that respond to local situations and the interests and values of the communities involved" (Seyfang and Smith, 2007, p. 585).

These processes of innovation differ in their conception and goals from those driven by the market and the state; grassroots innovation processes are generated by citizens who identify needs that may be social or of a more market-driven nature. We will pay closer attention to those which are socially motivated and which are usually promoted by selforganised groups from civil society, such as neighbourhood associations, groups of volunteers, cooperatives, social enterprises, informal groups, etc. Regarding resources, these grassroots innovations essentially obtain their resources based on voluntary contributions. Due to the way they operate and organise, they have different ways of relating to the public administration, according to their different visions and strategies (Smith et al., 2016; Boni et al., 2018b).

The literature recognises the enormous significance of these initiatives as well as the large number that emerged as a consequence of the 2008 financial crisis. Their contribution to the generation of alternative practices has been studied across a wide range of areas, from energy (Pellicer at al., 2017) and agro-ecology (authors, 2016) to eco-housing (Seyfang and Smith, 2007) or community currency (Seyfang and Longhurst, 2013). The aforementioned studies all show that these initiatives take very different forms, from cooperatives and community organisations to volunteer groups and social enterprises. The present study highlights the creation of new solutions, models and processes in wide variety of fields to advance towards more just and equitable societies. 
In short, it can be said that civil society is a powerful space for innovation-although it is not always visible-in very different fields.

The field of digital technology is no exception, and a good number of social innovation experiences are promoted (Smith and Ann, 2017). Their concerns range from material issues to those linked with political participation and action. All of these initiatives are examples of what is referred to in the present paper as Digital Grassroots Innovations (DGIs). They share-either explicitly or implicitly formulated-the same objective: to build a more democratic society through the use of digital technologies. However, their practices and strategies are very diverse. For example, at one extreme, DGls try to maintain a small size, operate on a small scale, maintain a more radical and experimental orientation, and relate only to very nearby experiences of a similar nature. At the other extreme, DGls focus their efforts on achieving greater growth, visibility and impact in numerical terms, in order to establish relationships with multiple actors with more power and visibility (Geels and Schot, 2007).

These different strategies correspond to differing ways of relating to the public administration. These can range from trying to remain protected, isolated and outside the public action-either due to mistrust, indifference, or from not understanding the benefits that can be obtained from the relationship-to trying to monitor or influence public policies, participate in them or implement them (Van den Bosch and Rotmans, 2008; Vicente and Matti, 2016).

The diversity of strategies is accompanied by diversity in the type of practices associated with technological innovation. In this research, for the purpose of characterising this type of innovation, we have used the classification proposed by Nesta (2015), which is described in the methodology section.

\section{Deepening democracy}

In order to better understand the contribution of grassroots innovation to more democratic and inclusive societies, we examine the literature of democracy building to grasp some key essential ideas. A large part of the literature that addresses the issue of democratic deficits is based on the observation that the deepening of democracy is achieved through more democracy. This democracy will trickle down and provide citizens with greater control over the processes of collective decisions or on collective matters (Gaventa, 2006). This helps us to understand the contribution that different DGI strategies and actions promoted by citizens play in the construction of democracy.

The work of Gaventa (2006) and Blas and Ibarra (2004) identify four central ideas in which to situate the perspectives in terms of the ways they seek to deepen democracy:

1) Deepen democracy by building civil society. This approach is characteristic of the liberal-democratic tradition. It is largely centred on the idea of representative democracy and gives a central role to the importance of having a strong, independent and structured civil society that operates as a watchdog of the administration. In fact, civil society is seen as a tool that controls the behaviour of the government, mobilises to make sure it meets the demands of the different actors, demands accountability and, in general, exercises a role of counterweight in relation to the power of the State (Carothers, 1999).

From this perspective, the strengthening of democracy is carried out, on the one hand, by generating a type of State that is more capable of responding to the demands of civil society, as well as increasing its transparency. And on the other, by building a robust and diversified civil society that monitors and articulates demands. 
In this sense, one can say that increased democracy would strengthen innovative initiatives aimed at, for example, promoting transparency through access to information and the use of open data generated in the number of daily transactions carried out by administrations and civil society. These operations can generate various mechanisms for monitoring public action, elaborating and channelling demands towards political representatives or advocating the revision or creation of public policies.

2) Deepen democracy through co-governance. This approach is more suited to a participatory approach to democracy. It concerns citizens having a direct role in the actions of the State, through the construction of more participative forms of governance and the co-production of policies and State action. From this approach, democracy is strengthened as citizens, either in an organised manner or even individually, engage directly in the structures and actions of the State, or dialogue with the administration and make decisions in relation to issues that concern them (Gaventa, 2004).

If we follow the differentiation established by Blas and Ibarra (2006), we can say that, within this perspective, we find two forms of relationship with the State: one that refers to participation in the State, and another that refers to participation with the Statealthough the separation between these two forms of participation is actually diffuse.

In the first case, citizens participate directly in the spaces or services of the public administration, in direct decision-making on public policies or in the co-management of public services. This would be the case of the decision-making spaces within the State in which different actors participate together with employers and trade unions-such as decision-making on labour or fiscal policy-or in the management of State spaces, infrastructures and services by social groups.

In the second case, participation with the State refers to the multiple mechanisms and procedures of citizen participation in which citizens or social organisations make decisions that affect the corresponding community to varying degrees. These decisions arise from an autonomous participatory citizen's space and in some way complement the decisions or the political will stemming from the political representatives. Examples of this are citizen's assemblies, participatory processes of community development, participatory budgets, consultations, etc.

In this case, the innovation processes that help deepen democracy are those where the administration opens working spaces with citizen's groups to help find solutions to the challenges they are facing. For example, in the provision of basic public services-a task that has usually been entrusted to private companies. There are also examples where citizens themselves have proposed solutions to prevent squandering the public budget, in cases such as the management of urban waste and public transport.

3) Deepen democracy outside the State. This approach is inspired by the most radical perspectives of democracy. Whilst the previous approaches give central importance to participation in or in relation to the State, this perspective emphasises the importance of constructing democratic spaces and processes outside the State. The main idea is that society can organise itself and generate different decision spaces (whether territorial, sectoral or otherwise) on everything that concerns it (Blas and lbarra, 2006). This perspective does not necessarily always deny the role of the State; however, in all cases it is committed to autonomy and self-management as fundamental forms of deepening democracy. 
Consequently, democracy is built by generating spaces for decision and action on all aspects of collective life. This includes actions such as the construction of assembly spaces for decision-making outside the State, or different areas of mutual aid or provision of goods and services outside the State and the market (for example, housing or educational or health services).

A clear global example of innovation that helps deepen democracy more radically and outside the State, is the anonymous creation of a digital currency such as Bitcoin. The monetary transactions in this innovation focus on trust among the same people who are part of the community, rather than depositing funds in a bank, which has its own economic interests.

4) Deepen democracy through the quality of deliberation. This approach is inspired by the work of authors on deliberative democracy. From this perspective, rather than in the relationship with the State or in the role of the State, the concern is placed on the nature and quality of the processes of dialogue and deliberation in the debates and discussions in the public sphere (Gaventa, 2006). Thus, civil society becomes the central place for democratisation as a place where life choices and ways to solve common problems are discussed (Dryzek, 2000). Under this approach, deepening democracy means improving the quality and conditions of this public debate.

From this perspective, actions that generate better channels of dialogue, offer information and means for quality debates, allow a more equal footing to the different actors that participate in the public debate, in terms of power and information, are all examples of deepening democracy through quality deliberation.

As has been indicated, these are not exclusive approaches, but rather different ways of understanding how democracy is built and deepened. They serve to help us understand the diversity of actions that can be promoted through DGI, as well as the complementarity between them, in order to devise forms of smart cities that contribute towards generating more democratic societies.

\section{Methodology}

Our research is a case study. Its most characteristic feature is the intensive and in-depth study of cases-understood as systems bounded by the limits required by the object of study, but framed in the global context where they occur (Stake 1995). The fieldwork was carried out between October 2016 and February 2017 and the cities for the study were selected by following a diversity criteria based on the activities and municipal plans being developed around the concept of smart city. The resulting study deals with Valencia, located on the Mediterranean Sea, and three cities from the North of Spain (Santander, Bilbao, and San Sebastián).

Santander is one the most representative cities of in Spain because it was the precursor of the Smart City Network in Spain. Bilbao is a city with a long industrial legacy and its City Council has been able to integrate this into its urban processes and developments. Although we found numerous DGIs, at first we did not find any references or links between the municipality and the smart city discourse; in fact, the city is not part of the Smart City Network. This contrast made it interesting, leading to it becoming an object of our study. San Sebastián was chosen for being a midpoint. The city shares the model of urban development linked to an industrial legacy, but it is also an active member of international networks and European smart city projects. Finally, Valencia was chosen 
as representative of a Spanish city which has had a change of government (from a conservative party to a more progressive one) and, with it, a change of direction in the conception of urban planning as well as understanding and management of technology, urbanism and other aspects relevant to the development of a smart city. The interest lay in analysing whether the change had been purely discursive, or if the integration of participatory techniques and initiatives in the creation of the smart city was discernible.

With regard to the selection of DGI initiatives, we followed the classification made by Nesta (2015). This classification collects more than 130 examples of global digital social innovation, categorising them into four tendencies.

- Open Hardware: understood as projects inspired by the "do it yourself" or maker movement. These projects make digital hardware available for people to adapt or create their own digital technology.

- Open Knowledge: large groups of citizens who join through online platforms to collectively create a new type of knowledge or social projects.

- Open Data: innovative ways of opening, capturing, using, analysing and interpreting data.

- Open Networks: networks of citizens who are developing new networks and infrastructures, to collectively share resources and solve problems.

This classification should not be understood as fixed. In fact, many of the DGls operate in more than one area. We interviewed and analysed 21 DGls, the names of which are detailed in Table 1:

\begin{tabular}{|l|l|l|}
\hline \multicolumn{1}{|c|}{ Name } & \multicolumn{1}{|c|}{ City } & \multicolumn{1}{|c|}{$\begin{array}{c}\text { Type } \\
\text { Innovation }\end{array}$} \\
\hline FabLab Santander & Santander & $\begin{array}{l}\text { Open } \\
\text { Hardware }\end{array}$ \\
\hline El Faradio & Santander & $\begin{array}{l}\text { Open } \\
\text { Knowledge }\end{array}$ \\
\hline Beta District & Santander & Open Data \\
\hline VLCHackerSpace & Valencia & $\begin{array}{l}\text { Open } \\
\text { Hardware }\end{array}$ \\
\hline FabLabUPV & Valencia & $\begin{array}{l}\text { Open } \\
\text { Hardware }\end{array}$ \\
\hline Yademás (Parcel.les) & Valencia & Open Network \\
\hline OuiShare & Valencia & Open Network \\
\hline
\end{tabular}




\begin{tabular}{|l|l|l|}
\hline VLCTechHub & Valencia & Open Network \\
\hline HubCívico & Valencia & Open Data \\
\hline UPV data & Valencia & Open Data \\
\hline Wikitoki & Bilbao & Open Network \\
\hline PezEstudio & Bilbao & $\begin{array}{l}\text { Open } \\
\text { Knowledge }\end{array}$ \\
\hline Collective Intelligences & Bilbao & $\begin{array}{l}\text { Open } \\
\text { Hardware }\end{array}$ \\
\hline Montera34, Basurama, Cadáveres Inmobiliarios, & Bilbao & Open Data \\
\hline Bilbaodatalab & Sebastián & $\begin{array}{l}\text { Open } \\
\text { Hardware }\end{array}$ \\
\hline Hirikilabs & Sebastián & Open Networks \\
\hline OpenyourGanbara & Sebastián & $\begin{array}{l}\text { Open } \\
\text { Hardware }\end{array}$ \\
\hline Salbao & $\begin{array}{l}\text { Open } \\
\text { Hardware }\end{array}$ \\
\hline
\end{tabular}

We carried out 18 interviews: seven in Valencia, four in Bilbao, three in San Sebastián and four in Santander. In order to understand the different technological responses that were emerging in the four cities, we conducted interviews with three experts on the subject and four policy-makers, related to the smart city project in each of the four cities.

The selection of the interviewees was based on personal contacts, recommendations from the interviewees themselves (snowballing), and in some cases, the result of searching social networks and attending events organised by them.

All this has been completed with an extensive literature review and direct observation in two forums related to DGI: CivicWise Factory Fest 7.0 held in the month of November 
2016 in the city of Valencia (http://civicfactory.com/ fest /) and the First Urban Innovation Week of Valencia, held in January 2017 (https://lasnaves.com/setmanainnovacio/es/)

We have chosen to follow a constructivist paradigm, which is affected by the "contamination of subjectivity" (Corbetta, 2003), assuming that part of our research will be based on the realities of those interviewed. In addition, our reality as researchers also has an influence on the study. That is why, from the outset, the ethical position in the interviews was guided by the communication of the results and validation of the collected data, as well as respect for the interviewees' opinions and anonymity, if required.

\section{Deepening democracy through DGI}

This section describes the type of digital innovation carried out by the DGI experiences in Santander, Valencia, Bilbao, and San Sebastián. It centres on how they understand participation and how they want to relate to the public sphere. Whilst we will see that there are notable differences, there is no doubt that together they constitute a wide repertoire of initiatives that consider how to deepen democracy through digital technology.

\section{Santander}

In Santander, we found three DGI experiences: FabLab Santander, El Faradio and Distrito Beta. FabLab Santander [1] was created in 2013 by a group of makers with the intention of making technology accessible to citizens, specifically, digital manufacturing tools (printing and modelling in 3D, basic electronics, Arduino, etc.). They intend, therefore, to bring technology and knowledge to society openly and freely. According to the classification made by Nesta (2015), the FabLab is of the Open Hardware type, as its members create devices and machines that respect the freedom of their creators to control their technology and, at the same time, they share knowledge and promote the open exchange of designs. This group does not have blind faith in technology as a solution to problems, but they see technology as a tool that enables changes to be made.

El Faradio [2] is composed of a digital newspaper and two radio programmes. They try to make a different kind of journalism, giving prominence to the cultural world, social groups, local and business initiatives, citizen's platforms, disseminating individual and collective grievances, demonstrations, etc. El Faradio is an Open Knowledge (Nesta, 2015) initiative, since it shares knowledge openly and serves as a platform and voice for citizens' movements to express their demands.

Distrito Beta [3] is a co-working space founded in 2013. In this space events, meetings, workshops and courses take place with the aim of bringing the culture of entrepreneurship and new technologies closer to citizens. It is this approach to citizenship that differentiates Distrito Beta from other similar activities that can be carried out by the City Council or training companies. With regard to technology, the focus is on Open Data (Nesta, 2015), since the City Council's open data set has been used to create tools of interest for citizens. The most widely used tool was an application to explore the tourist attractions of the city through quizzes and games to accumulate points and, at the same time, obtain discounts, tickets or prizes.

None of these experiences is more than five years old. One of the experiences analysed, El Faradio, explains that this is due to the lack of critical spirit that exists in Santander and the advanced age of the population, which is detached from new technologies. In addition, they criticise the City Council, claiming that it has always tried to delegitimise associations and movements that are critical of its management. 
In March 2017, Beta District co-working closed its doors for the last time due to the economic infeasibility of the project. Although Santander is promoted as a smart city nationally and internationally, it has not been able to drive DGl. District Beta thinks that it should be a direct responsibility of the City council: "There are no stimuli on the part of the City Council. We made an app that won a contest they had organised, but they did not want to buy it." (December 2016).

Regarding the vision of digital technology, El Faradio, FabLab and District Beta are similar in their approach of sharing knowledge and placing technology at the service of citizens, either as a means of alternative communication, as creators of technological artefacts, or providing information relevant to citizenship. They represent, therefore, a different vision of deepening democracy.

El Faradio deepens democracy by building civil society because they facilitate access to information, are always vigilant against injustices and support various groups in the demands they generate. Likewise, the use of digital technology also allows El Faradio to propose a better deliberative democracy, since it generates channels of dialogue for social groups, offers information that is not normally available in conventional media, and reports on people and collectives that are disadvantaged in terms of power and information. The FabLab has less social impact, but it makes efforts to share its knowledge, as evidenced by its open-door sessions on Fridays or courses that are open to the general public. It is an experience that works outside the City Council. They, therefore, deepen democracy outside the State. Finally, Distrito Beta uses technology to provide information to the public. They are placed, mainly, among those groups that promote democracy by building civil society (representative democracy), as demonstrated by the applications they have made using the City Council's Open Data sets with the aim of facilitating citizens' access to information.

\section{Valencia}

In Valencia, seven experiences were analysed. They have different organisational forms, technological approaches and strategies related to administration.

VLCHackerSpace [4] was created in 2012 when a group of friends got together to "Thinkr" with gadgets (HackerSpace, November 2016). In 2013, it was established as a maker association and, in 2015, due to an increase in members, they acquired a premises for the group. Currently, the association features the participation of 22 people who defend the advantages of free code and do it yourself. They also hold workshops in the neighbourhood and support other groups in the area. When interviewed, they indicated that their interest does not lie in their relationship with the local administration, which is minimal and unidirectional (from the administration towards them-when they are invited to make talks), but in active and local learning (through workshops in the neighbourhood) and having a good social atmosphere in the group.

FabLabUPV [5] is a space for innovation in the creation of technological devices using free or open software. They work within the Universitat Politècnica de València and their technological focus is on Open Hardware (Nesta, 2015). It has many similarities with the VLCHackerSpace; in fact, some of the members, who are mostly men, have moved from one to the other. They interact with the City Council to carry out projects presented in calls, but they feel that their principles are not shared by the administration. In this sense, their representative states: "We have proposed to the City Council of Valencia that the 
city should join the FabCity network, but [...] they haven't taken any notice of us" (October, 2016).

Yademás (Parcel.les) [6] is a project from a consultancy company. Thanks to having won the Second Valencian Social Innovation Awards in 2016, sponsored by the City Council, they developed two applications allowing ecological gardens in the city to connect with each other and make improvements. Their technological focus is on Open Network, and they enjoy a good relationship with the City Council.

OuiShare [7] originated in Paris and is now present in various cities. This group is mainly interested in the collaborative economy and entrepreneurship. Through its website and the use of social networks, it connects people interested in these issues.

VLCTechHub [8] emerged in 2012 as an initiative of one person who created an event newsletter to coordinate the various stakeholders interested in technological changes. Currently, it is the largest independent agenda for technological events in Valencia. It operates outside of any actions on the part of the local government, although it has been invited to deliver presentations organised by the City Council.

HubCívico [9] is recognised as a social collective (composed of civic hackers) that aims to escape from the logic of the system of production and consumption. They use digital technologies to provide information to citizens (through the use of data journalism and data mining, etc.) that is different from that which usually appears on official pages. They also intend to monitor public accounts to make the City Council more accountable. Finally, they offer and disseminate training opportunities in the use of new technologies to citizens interested in playing a more active role in monitoring public policy. Its relationship with the City Council is very limited, but it does collaborate with the Chair of the Open Government (Govern Obert) of the Universitat Politècnica de València, which is financed by the Citizen Participation Department of Valencia City Council.

Finally, Data UPV [10] is a recently created student association (2016) that emerged as a result of a hackathon organised by Telefónica at the Universitat Politècnica de València. Its main activity is the organisation of data competitions, contests for the use of open data and other events in order to process and open the available data to the public.

As we have seen, the ways they relate to the public administration are very diverse: from the most extreme maker perspective (that of the VLCHackerSpace), which that does not want to have any relationship with the administration; to the Parcel.les project, which was created under the auspices of the City Council itself. The other initiatives are located between these two extremes: FabLabUPV, makers who participate in public calls; Data UPV, which carries out its most relevant activities in the municipal offices; and HubCívico, which oversees the work of the administration, but also collaborates with a chair that is sponsored by the City Council.

All these initiatives share the common feature of using digital technology at the service of citizens, from the manufacture of technological devices to the use of open data. In this sense, OuiShare is the most different initiative. Its vocation is to connect people interested in entrepreneurship through the collaborative economy. Therefore, unlike the others, we can consider that it is the only initiative that does not aim to deepen democracy. The others do, but do so differently. The makers operate outside the Statewhich was also the case in Santander. HubCívico makes the information existing in the open data available to the public, in order to empower citizens and allow them to gain control and exert power on the public administration. However, in the case of DataUPV, 
although they share the same type of digital technology, the role they play is more to help provide information that can be understood by citizens. In this sense, we could say that its vocation is more to deepen democracy through the quality of deliberation, by providing a type of information that, due to its technological complexity, usually remains outside the reach of citizens. In the case of Parcel.les, the digital innovation that they propose is in the line of promoting the most sustainable use of the natural resources of the city of Valencia (in this case, Valencia's fertile fields) putting organic farmers and people interested in urban gardens in contact with each other. It is a way of deepening democracy outside the State.

\section{Bilbao}

In the city of Bilbao, four people were interviewed, together representing a multiplicity of DGI experiences. They are in constant connection, which means that people involved in one group are frequently also involved in others, depending on the project they are carrying out.

Wikitoki [11] has its technological focus on Open Networks (Nesta, 2015) since it aspires to make use of technology to create citizen's networks that develop solutions to urban problems and provide a collective response to them. It is the most representative group since it features 25 people from different companies, groups or associations working together. They pay a monthly rent to the City Council to use the public infrastructure, but the activity performed there is completely autonomous. In Wikitoki, there are committees responsible for various tasks and where decisions on new members, projects, alliances, and even decisions on everyday aspects - such as cleaning - are taken in an assemblyled manner based on consensus. People who participate in Wikitoki usually have no relationship with the public administration, although they have recently begun a collaboration with the Basque Government to create a kind of digital yellow pages of a neighbourhood of Bilbao in order to generate a community spirit and publicise the work of groups that make sustainable furniture

Another experience of DGI, but one with a greater focus on Open Knowledge (Nesta, 2015), is PezEstudio [12]. It aims to rethink the smart city from the point of view of technology, design and sustainability. From this relationship about how we live, the design of the city and what systems we are using, PezEstudio relies on the Participatory Action Research methodology as a first step to raise questions about the kind of city we have, and the kind that we want to have.

The interviewee from PezEstudio is also co-creator of Collective Intelligences [13]. This group, which could be classified as an Open Network (like Wikitoki), is made up of ten people and is located in various Spanish, European and Latin American cities. It has a totally digital format and is a place for the consultation and contribution of nonstandardised and informal constructive solutions. Like PezEstudio, Collective Intelligences proposes rethinking the smart city from a collective perspective. This is how it defines itself in one of its projects:

BilbaoCommons is a public space open to citizen use, an experimental prototype of a collective smart city that covers the neighbourhoods of Bilbao. It is a place to imagine, wish, build and implement a city based on collective intelligence and participatory processes.

Another Wikitoki member who was interviewed describes five other DGI projects with a technological focus on Open Data (Nesta, 2015): Montera34 [14], Basurama [15], Cadáveres Inmobiliarios [16], and Bilbaodatalab [17] are the names of the sets of 
solutions and ideas on how to take advantage of technology to improve or denounce a situation. These initiatives, which date from 2001 to the present, focus on "the use of data so that everyone can set their own agenda" (Basurama, December 2016). They have a clear emphasis on social demands and grievances, supported by information obtained from crossing data and representing it in maps, graphs or other editable free formats. Each of these initiatives aims to improve the quality of information available to the public in order to improve their decisions. They maintain contact with other initiatives in Spain, South Africa, and Brazil.

Several of those interviewed have also participated in one of the experiences that is most visible to the general public: EspacioOpen [18]. This space began in a self-managed way eight years ago and currently includes the OpenyourGanbara (an alternative cultural event that opens its doors to the public every Sunday morning), and a FabLab, or technological space, that offers material resources and knowledge for the creation of prototypes and developments. Additionally, it is also a maker space that organises, among many other meetings and training activities, the Bilbao Maker Faire [19]:

Maker Faire is the largest fair of inventors and creators in the world, a showcase of inventions, creativity and ingenuity designed for all audiences, in addition to a celebration of the Maker movement. It is a place where people teach the world their creations and share their knowledge with those who want to learn. (From their website)

The last group interviewed, and the only group that does not belong to the Wikitoki "ecosystem", is the Deusto Free Software Group [20]. It emerged in the Deusto University Computer Engineer School at the end of the 1990s, under the auspices of a professor and a group of students who wanted to install free software. Currently the group has lost strength. According to one of its members, this is due to the fact that the University and public or private entities use the cloud-which is controlled by Googlefor their data (Grupo Software Libre, December 2016). Despite this, the group continues to meet sporadically and hold workshops where open data and free software intermingle with values of technological sovereignty, control and privacy, or equity and power.

The case of Bilbao perfectly illustrates the existence of a DGI ecosystem. In the crucible of the Wikitoki space, various initiatives that share the use of digital technology at the service of citizens arise, practising different models of deepening democracy. There are examples of more direct action of denouncement and political incidence through the use of open data (the cases of Basurama, Montera34, Cadáveres Inmobiliarios or Bilbaodatalab) that correspond to a proposal to build a strong civil society that acts as a counter-power. We also find initiatives to build democracy by creating design solutions adapted to the needs of citizens (PezEstudio and InteligenciasColectivas). In Bilbao, we find experiences that dispute the concept of smart city and redefine it from the collective viewpoint. In our opinion, these are attempts to expand the quality of deliberation on the concept of a digital city. However, we cannot affirm that we are dealing with a space of co-governance of the smart city since the priorities of the Bilbao City Council are different. As one of the interviewees of PezEstudio affirms: "in the Basque Country, culture is supported, and public-private collaboration is offered, but there are still paths that must be followed [...] and the priority is usually industry" (PezEstudio, December 2016).

\section{San Sebastián}

In San Sebastián, individuals from three DGI experiences were interviewed: Hirikilabs, Güifi and Aralar Permaculture. The latter two operate from the ImpactHub [21] which is 
based in Tabakalera. The ImpactHub is defined as an international network of entrepreneurs, activists, creatives and professionals who share the vision of generating a positive impact on society through collaborative projects

Hirikilabs [22] is a maker organisation dedicated to open hardware, which is defined as a digital culture and technology laboratory. Sponsored by public funds from the City Council (which provides the headquarters in Tabakalera and economic support), Hirikilabs offers a space, tools and training to work around the social, critical, creative and collaborative use of digital technologies. It is defined as a space for experimentation and prototyping and, in the interview, its members stressed the difference between a seedbed or shuttle of ideas and the Hirikilabs space. In the latter, one can propose activities, work with cutting-edge technology, collaborate, but always from the city perspective and not for profit. It is such an innovative concept that, according to its members, it is as difficult for the general public to assimilate it as for the public administration itself.

One of the members of Hirikilabs is also the driving force behind the second initiative: Güifi. It works to create a free, open and neutral telecommunications network, which is mostly wireless - the Guifi.net network. This is a cable-free network, which has more than 32,900 nodes, located mostly in Catalonia. Today, it is the largest free network in the world, and in the Basque Country it is expanding from the Ping project [23]. As the person interviewed pointed out "my personal battle is technological sovereignty [...] we must change the concept of responsibility and generate a chain of responsibilities so that we can all be sovereign as individuals, society and country" (Güifi, December 2016).

The emphasis on the concept of technological sovereignty is also the focus of the work of the third initiative, Permacultura Aralar [24]. Like Güifi, they use the ImpactHub in the Tabakalera building. The creator of Permacultura Aralar is a member of the maker movement and a regular participant of EspacioOpen in Bilbao.

All the experiences interviewed are very critical of the smart city concept. In the words of the Güifi member, the smart city is "a conspiracy by companies to maintain power in the hands of a few, which people do not reject because they are afraid of not having someone to hold accountable if the system collapses" (Güifi, December 2016). Instead of the smart city, DGI experiences prefer to talk about the freedom of individuals to make use of technology. The role of the organisations that embrace the maker movement is "to show that technology is a tool that, by learning with others, you can use [...] and make it accessible. We ask ourselves what would happen if we suddenly put industrial technology, or technology that is not normally for everyone, in the hands of the public" (Hirikilabs, December 2016).

In relation to the deepening of democracy, it can be seen how DGI initiatives are deepening democracy outside the State; they are the only ones that speak clearly about technological sovereignty and how digital technology puts solutions that do not depend on the market at the service of citizens. Interestingly, this participation outside the State takes place in a public space (Tabakalera) and receives, on occasion, public subsidies. Likewise, the examples of the San Sebastián initiatives are also a way to deepen democracy by improving the quality of the debate, and making citizens aware of the potential of digital technology.

\section{Conclusions. Towards a more participatory understanding of the smart city}


Although the concept of the smart city is rejected by most of the experiences interviewed, due to its mercantilist and technocratic connotations, in the DGls studied we find numerous and diverse practices of a participative construction of the city from the digital perspective.

For example, experiences linked to the maker movement (open hardware) build new democratic spaces outside the State proposing that groups of people interested in digital technology come together to find solutions to issues that affect the group itself or people with whom it has a relationship. Although these democratic spaces are autonomous, they may have a variety of different relations with the public administration: some groups prefer to have no relation (Santander and Valencia), while other groups opt for more collaborative strategies with the public administration, as is the case in Bilbao or San Sebastián.

Some open data experiences deepen democracy by strengthening civil society as a space of counter-power and vigilance against the State, or by generating new citizen demands. Other open data initiatives also contribute to improving the quality of democratic processes, since they offer citizens tools and information that come from these data to improve citizens' capacity for dialogue, debate and proposals. The open data groups also have varying strategies with regard to the public administration-from being totally autonomous to collaborating in the realisation of activities such as data marathons or similar events.

Within the Open Knowledge and Open Networks movement there are also various initiatives that build or strengthen democratic spaces and processes, as well as different strategies towards the public administration. There are more openly politicised experiences that generate websites, platforms and information that mobilises citizens and question the work of the public administration (in this sense they work to build civil society), to other less politicised initiatives that are oriented towards strengthening relationships and creativity among people interested in innovation, which generate new opportunities for participation.

In all cases, regardless of the strategy they use to relate-or not-with the administrations, the DGI experiences constitute a varied repertoire of initiatives where the purpose of digital innovation is not only to solve problems that affect citizens, but also to make spaces for the creation and empowerment of critical citizens that are vigilant of the actions of public and private powers. In this sense, innovation not only refers to the design and materialisation of new products or processes, but also to the contribution that the DGI is making to the construction of citizenship and, therefore, to the construction of democracy.

It is important that, in the construction of a participatory smart city, the administrationsif they truly want to embrace participation-should involve the citizenry, clearly identifying what role democratic participation should play. A democratic and comprehensive participatory vision should recognise the importance of innovation processes coming from below, driven by citizens' initiatives. It should value the multiplicity of forms, spaces and mechanisms of democratic construction, and it should consider citizen participation and democracy not only as a means, but also as ends in themselves, which cannot be subordinated to a technocratic logic that ultimately seeks a more efficient management of the city as an end in itself.

There are multiple ways of relating with and supporting innovation from below. The initiatives may not require public action at all, or require various types of actions by the administration. These actions can range from ensuring that the initiative works without 
interference to establishing dialogue mechanisms or offering technical, logistical or economic support. Therefore, an administration aligned with a participatory vision of the smart city should recognise these demands and needs are different and act accordingly.

Finally, ecosystems of digital social innovation can be found within these territories. That is, there are communities and groups of actors that maintain various types of relationships, which are always changing and are constantly evolving. Consequently, we recommend that the administrations should recognise these ecosystems, and try to understand them in a way that protects them and encourages their evolution. Once again, being aware of the strategies and demands of the actors is fundamental in this regard. 